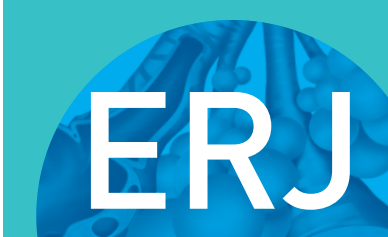

open research

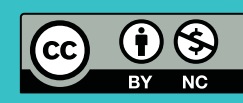

\section{Breastfeeding and respiratory tract infections during the first 2 years of life}

To the Editor:

Breastfeeding protects against respiratory tract infections (RTIs) in infants [1-3], but whether its effects persist beyond that age is not well understood. Some studies have reported that protection diminishes soon after weaning [2], while others have found that it extends until the age of 2 years [4] or more [5, 6]. It is noteworthy that many previous studies grouped RTIs broadly into upper or lower tract infections, rather than studying specific diseases [3, 7], and few adjusted adequately for confounding factors [5] or investigated a possible effect modification by sex, which had been suggested by several studies showing a stronger protection in girls $[8,9]$.

This study aimed to quantify the protective effect of breastfeeding against RTIs during the first 2 years of life, while adjusting for potential confounding factors and testing whether the effect varied by sex.

We analysed data from the Leicester Respiratory Cohorts, a population-based random sample of children from Leicestershire, UK, which has been described in detail elsewhere [10]. For this analysis we included only children born between 1996 and 1997 who were aged 1-1.99 years at the date of the first survey in 1998. Parents completed a standardised questionnaire that requested detailed information on breastfeeding and respiratory symptoms. We assessed the duration of breastfeeding (no breastfeeding, $\leqslant 6$ months or $>6$ months), the prevalence of frequent colds ( $>6$ episodes), ear infections and croup within the last 12 months, and any episodes of bronchiolitis or pneumonia. We extracted perinatal data and demographic information from maternity records. The Leicestershire Health Authority Research Ethics Committee approved the study.

The survey requested information on a number of RTIs for each child, so we first performed an omnibus logistic regression to determine whether breastfeeding was associated with the occurrence of any RTI. By reforming the data into long format, this omnibus logistic regression also adjusted for the clustering of observations within each child [11]. Following a significant omnibus test, we performed unadjusted and adjusted logistic regressions to determine which RTIs were affected by breastfeeding practice. Adjusted models controlled for sex, ethnicity, socioeconomic status (Townsend deprivation score [12]), perinatal factors (gestational age, birthweight, birth season), environmental factors (pre- and post-natal maternal smoking, number of older siblings, day care attendance) and parental history of asthma, hay fever and bronchitis. We tested for effect modification by sex by adding interaction terms into adjusted models. Finally, we performed a sensitivity analysis including a subgroup of children with information on exact breastfeeding duration, by using breastfeeding as a continuous exposure, rather than categorical. All analyses were performed in Stata (version 14.2, Stata Corporation, Austin, TX, USA).

The survey in 1998 was sent to 5400 families with children aged between 1 and 1.99 years. Questionnaires were returned by 4100 parents (response rate of 76\%). After excluding 47 children who had no breastfeeding information and 13 children born extremely prematurely (gestational age of <28 weeks [13]), 4040 children remained in the analysis. Of these, $52 \%$ were boys, $81 \%$ were white and $19 \%$ were of South Asian ethnic origin, 1659 (41\%) had never been breastfed, 1639 (41\%) had been breastfed for $\leqslant 6$ months and $742(18 \%)$ for $>6$ months. Of the 4040 included children, 769 (19\%) were reported by their parents to have had frequent colds, 1685 (42\%) ear infections and 293 (7\%) croup within the last 12 months. Any episodes of bronchiolitis were reported for 453 children (11\%) and pneumonia for 53 (1\%).

@ERSpublications

Breastfeeding and respiratory tract infections http://ow.ly/Isd9309JS69

Cite this article as: Wang J, Ramette A, Jurca M, et al. Breastfeeding and respiratory tract infections during the first 2 years of life. ERJ Open Res 2017; 3: 00143-2016 [https://doi.org/10.1183/ 23120541.00143-2016].

Copyright $\odot$ ERS 2017. This article is open access and distributed under the terms of the Creative Commons Attribution Non-Commercial Licence 4.0. 
When considering all aforementioned infections together, we found evidence for an association between breastfeeding and any of the five infections (omnibus logistic regression test, $\mathrm{p}=0.0314$ ). Proceeding with individual unadjusted logistic regression tests, we found that breastfeeding protected against bronchiolitis during the first 2 years of life, with an odds ratio (OR) of $0.79,95 \%$ confidence interval (CI) of $0.64-0.97$ and p-value of 0.028 for breastfeeding for $\leqslant 6$ months and OR $0.68,95 \%$ CI $0.51-0.91$ and $p=0.009$ for breastfeeding for $>6$ months compared to children who had never been breastfed (table 1). We also found a weak protective effect of breastfeeding for $>6$ months against ear infections (OR 0.84, 95\% CI 0.70-0.99, $\mathrm{p}=0.048$ ) (table 1). We did not find any associations between breastfeeding and frequent colds, croup or pneumonia. After adjusting for confounding factors, only breastfeeding for $>6$ months remained protective against bronchiolitis (adjusted OR 0.72, 95\% CI 0.52-0.97, p=0.034) (table 1). There was no statistical evidence of effect modification by sex for any RTIs ( $p$-values of interaction terms ranging from 0.059 to 0.953). Exact information on breastfeeding duration was available for 2286 children. In this subgroup,

TABLE 1 Associations between breastfeeding duration and respiratory tract infections

\begin{tabular}{|c|c|c|c|c|}
\hline \multirow[t]{2}{*}{ Breastfeeding duration as categorical exposure } & \multicolumn{2}{|c|}{ Unadjusted ( $n=4040)$} & \multicolumn{2}{|c|}{ Adjusted $^{\#}(\mathrm{n}=3963)$} \\
\hline & OR $(95 \% \mathrm{CI})$ & p-value & OR $(95 \% \mathrm{CI})$ & p-value \\
\hline \multicolumn{5}{|l|}{ Frequent colds } \\
\hline No breastfeeding & 1.00 & & 1.00 & \\
\hline$\leqslant 6$ months & $0.97(0.82-1.16)$ & 0.749 & $1.00(0.83-1.21)$ & 0.985 \\
\hline$>6$ months & $0.99(0.80-1.24)$ & 0.958 & $1.01(0.80-1.27)$ & 0.953 \\
\hline \multicolumn{5}{|l|}{ Ear infections } \\
\hline No breastfeeding & 1.00 & & 1.00 & \\
\hline$\leqslant 6$ months & $0.91(0.80-1.05)$ & 0.198 & $0.97(0.84-1.13)$ & 0.710 \\
\hline$>6$ months & $0.84(0.70-0.99)$ & 0.048 & $0.88(0.73-1.06)$ & 0.177 \\
\hline \multicolumn{5}{|l|}{ Croup } \\
\hline No breastfeeding & 1.00 & & 1.00 & \\
\hline$\leqslant 6$ months & $0.92(0.71-1.19)$ & 0.523 & $0.95(0.72-1.26)$ & 0.738 \\
\hline$>6$ months & $0.92(0.66-1.28)$ & 0.612 & $0.86(0.60-1.23)$ & 0.408 \\
\hline \multicolumn{5}{|l|}{ Bronchiolitis } \\
\hline No breastfeeding & 1.00 & & 1.00 & \\
\hline$\leqslant 6$ months & $0.79(0.64-0.97)$ & 0.028 & $0.89(0.70-1.12)$ & 0.316 \\
\hline$>6$ months & $0.68(0.51-0.91)$ & 0.009 & $0.72(0.52-0.97)$ & 0.034 \\
\hline \multicolumn{5}{|l|}{ Pneumonia } \\
\hline No breastfeeding & 1.00 & & 1.00 & \\
\hline$\leqslant 6$ months & $1.28(0.70-2.35)$ & 0.421 & $1.44(0.76-2.73)$ & 0.260 \\
\hline$>6$ months & $1.18(0.55-2.55)$ & 0.675 & $1.11(0.48-2.55)$ & 0.810 \\
\hline \multirow[t]{2}{*}{ Breastfeeding duration as continuous exposure } & \multicolumn{2}{|c|}{ Unadjusted ( $n=2286)$} & \multicolumn{2}{|c|}{ Adjusted $^{\#}$ (n=2248) } \\
\hline & $O R^{11}(95 \% \mathrm{CI})$ & p-value & $O R^{11}(95 \% \mathrm{CI})$ & p-value \\
\hline \multicolumn{5}{|l|}{ Frequent colds } \\
\hline No breastfeeding & 1.00 & & 1.00 & \\
\hline Breastfeeding (per month) & $1.00(0.98-1.03)$ & 0.736 & $1.00(0.98-1.03)$ & 0.734 \\
\hline \multicolumn{5}{|l|}{ Ear infections } \\
\hline No breastfeeding & 1.00 & & 1.00 & \\
\hline Breastfeeding (per month) & $0.99(0.97-1.01)$ & 0.277 & $0.99(0.97-1.01)$ & 0.408 \\
\hline \multicolumn{5}{|l|}{ Croup } \\
\hline No breastfeeding & 1.00 & & 1.00 & \\
\hline Breastfeeding (per month) & $1.00(0.96-1.04)$ & 0.827 & $0.99(0.95-1.03)$ & 0.571 \\
\hline \multicolumn{5}{|l|}{ Bronchiolitis } \\
\hline No breastfeeding & 1.00 & & 1.00 & \\
\hline Breastfeeding (per month) & $0.95(0.91-0.99)$ & 0.016 & $0.96(0.92-1.00)$ & 0.054 \\
\hline \multicolumn{5}{|l|}{ Pneumonia } \\
\hline No breastfeeding & 1.00 & & 1.00 & \\
\hline Breastfeeding (per month) & $1.00(0.91-1.10)$ & 0.972 & $1.00(0.90-1.11)$ & 0.991 \\
\hline \multicolumn{5}{|c|}{$\begin{array}{l}\text { Baseline group: children that had never been breastfed. " } \text { : for sex, ethnicity, socioeconomic status } \\
\text { (Townsend deprivation score), perinatal factors (gestational age, birthweight, birth season), environmental } \\
\text { factors (pre- and post-natal maternal smoking, number of older siblings, day care attendance) and family } \\
\text { history of asthma, hay fever and bronchitis. ๆ: ORs here are presented as odds with every 1-month increase } \\
\text { of breastfeeding duration compared to odds of children who had never been breastfed. }\end{array}$} \\
\hline
\end{tabular}


breastfeeding duration ranged from 0 to 48 months (mean=1.72, $\mathrm{SD}=4.18$ ). The sensitivity analysis using this exposure also found evidence for a protective effect of breastfeeding against bronchiolitis, with a crude OR of 0.95 per month of breastfeeding (95\% CI 0.91-0.99, p=0.016) and an adjusted OR of 0.96 per month of breastfeeding (95\% CI 0.92-1.00, p=0.054; table 1).

In summary, this large study from the UK found very limited evidence of a protective effect of breastfeeding against all types of RTIs during the first 2 years of life. However, the data suggest that extended breastfeeding ( $>6$ months) might protect against bronchiolitis.

The prevalence of ever breastfeeding in our study is lower than in other studies from the UK or USA $[2,4,6]$, perhaps because our study population was born earlier and at that time breastfeeding had not been well promoted in the UK. The prevalence of RTIs in our study population is comparable with other studies $[2,4]$. It could be speculated that, while breastfeeding confers limited protection against becoming infected with a virus, such as colds, it could prevent viral infection from developing into bronchiolitis through improved host defence, but the mechanisms for this would need to be identified. We did not find clear evidence that breastfeeding protects against ear infections during the first 2 years of life, in contrast to the report by BowATTE et al. [14]. However, there was a trend towards a protection against ear infections and a dose response with longer breastfeeding duration. The majority of the studies on the effect of breastfeeding on pneumonia come from low- and middle-income countries, such as India and Brazil, said HorTA et al. [5] in a systematic review, where children usually have a higher exposure to infections, a poorer nutritional status and reduced access to healthcare.

The strengths of our study are the large unselected cohort and the fact that we investigated several RTIs and could control for many confounding factors. Although we relied on parent reports for breastfeeding and RTIs, our questionnaire had excellent repeatability (Cohen's kappa $(\kappa)$ : 0.80-0.96) for breastfeeding [15]. In addition, we were able to explore the effects of breastfeeding as a continuous exposure, which supported our main finding. The main limitation of the study is that we had no information on the exact dates of infections and insufficient resolution to determine the severity of infections. Future studies should be prospective, and assess dates and severity of upper and lower respiratory infections.

In conclusion, this study suggests that prolonged breastfeeding might protect against bronchiolitis during the first 2 years of life in developed countries. This provides further evidence in favour of improving breastfeeding practice worldwide.

Jingying Wang $\odot^{1}$, Alban Ramette $\odot^{1}$, Maja Jurca $\odot^{1}$, Myrofora Goutaki $\odot^{1,2}$, Caroline S. Beardsmore $\odot^{3}$ and Claudia E. Kuehni $\circledast^{1,2}$

${ }^{1}$ Institute of Social and Preventive Medicine, University of Bern, Bern, Switzerland. ${ }^{2}$ Paediatric Respiratory Medicine, Children's University Hospital of Bern, Bern, Switzerland. ${ }^{3}$ Department of Infection, Immunity and Inflammation, University of Leicester, Leicester, UK.

Correspondence: Claudia E. Kuehni, Institute of Social and Preventive Medicine, Finkenhubelweg 11, CH3012 Bern, Switzerland. E-mail: claudia.kuehni@ispm.unibe.ch

Received: Nov 302016 | Accepted: Feb 122017

Support statement: The Swiss National Science Foundation (32003B-144068, 32003B_162820 and PDFMP3 137033), Asthma UK (07/048) and the China Scholarship Council (CSC201308340039) funded this study. Funding information for this article has been deposited with the Crossref Funder Registry.

Conflict of interest: None declared.

Acknowledgements: The authors thank the parents of the Leicester Respiratory Cohorts children for completing the questionnaires, Cristian Dogaru (School of Applied Social Science, University Campus Suffolk, Ipswich, UK) for contributing to dataset management, and Kali Tal (Institute of Social and Preventive Medicine, Bern, Switzerland) for her editorial assistance.

C.E. Kuehni and J. Wang developed the concept and designed the study. J. Wang performed the statistical analyses under the guidance of A. Ramette. C.E. Kuehni, J. Wang, M. Goutaki and A. Ramette drafted the manuscript, and all authors contributed to iterations and approved the final version. All authors take final responsibility for the content of this article.

\section{References}

1 Duijts L, Jaddoe VW, Hofman A, et al. Prolonged and exclusive breastfeeding reduces the risk of infectious diseases in infancy. Pediatrics 2010; 126: e18-e25.

2 Quigley MA, Kelly YJ, Sacker A. Breastfeeding and hospitalization for diarrheal and respiratory infection in the United Kingdom Millennium Cohort Study. Pediatrics 2007; 119: e837-e842. 
3 Tarrant M, Kwok MK, Lam TH, et al. Breast-feeding and childhood hospitalizations for infections. Epidemiology 2010; 21: 847-854.

4 Hetzner NM, Razza RA, Malone LM, et al. Associations among feeding behaviors during infancy and child illness at two years. Matern Child Health J 2009; 13: 795-805.

5 Horta BL, Victora CG. Short-term Effects of Breastfeeding: A Systematic Review on the Benefits of Breastfeeding on Diarrhoea and Pneumonia Mortality. Geneva, WHO, 2013.

6 Li R, Dee D, Li CM, et al. Breastfeeding and risk of infections at 6 years. Pediatrics 2014; 134: Suppl. 1, S13-S20.

7 Zhang G, Lai CT, Hartmann P, et al. Anti-infective proteins in breast milk and asthma-associated phenotypes during early childhood. Pediatr Allergy Immunol 2014; 25: 544-551.

8 Klein MI, Bergel E, Gibbons L, et al. Differential gender response to respiratory infections and to the protective effect of breast milk in preterm infants. Pediatrics 2008; 121: e1510-e1516.

9 Sinha A, Madden J, Ross-Degnan D, et al. Reduced risk of neonatal respiratory infections among breastfed girls but not boys. Pediatrics 2003; 112: e303

10 Kuehni CE, Brooke AM, Strippoli MP, et al. Cohort profile: the Leicester Respiratory Cohorts. Int J Epidemiol 2007; 36: 977-985

11 Jann B. Tabulation of multiple responses. Stata J 2005; 5: 99-122.

12 Townsend P. Poverty in the United Kingdom. London, Allen Lane and Penguin Books, 1979.

13 Sohn M, Ahn Y, Lee S. Assessment of primitive reflexes in high-risk newborns. J Clin Med Res 2011; 3: 285-290.

14 Bowatte G, Tham R, Allen KJ, et al. Breastfeeding and childhood acute otitis media: a systematic review and meta-analysis. Acta Paediatr 2015; 104: 85-95.

15 Strippoli MP, Silverman M, Michel G, et al. A parent-completed respiratory questionnaire for 1-year-old children: repeatability. Arch Dis Child 2007; 92: 861-865. 